\title{
Metastatic Malignant Neoplasm in the Leptomeninges
}

National Cancer Institute

\section{Source}

National Cancer Institute. Metastatic Malignant Neoplasm in the Leptomeninges. NCI

Thesaurus. Code C3814.

A malignant neoplasm that has spread from its original site of growth to the leptomeninges. 